\title{
Erector spinae plane block: an innovation or a delusion?
}

\author{
Seunguk Bang ${ }^{1,2}$ \\ Department of Anesthesiology and Pain Medicine, ${ }^{1}$ Daejeon St. Mary's Hospital, College of Medicine, The Catholic \\ University of Korea, Daejeon, ${ }^{2}$ College of Medicine, The Catholic University of Korea, Seoul, Korea
}

In this issue of the Korean Journal of Anesthesiology, an interesting paper focusing on the new application of the erector spinae plane block (ESPB) was published. Elkoundi et al. [1] reported that the ESPB at the lumbar level provided effective analgesia after pediatric hip surgery.

Initially reported by Dr. Forero et al. [2] in 2016 to provide effective analgesia after thoracic surgery, the ESPB is a new technique of interfascial plane block between the thoracic transverse process and the overriding erector spinae muscle. Their study involved the injection of local anesthetics between the transverse process and the erector spinae muscle wide-spreading towards the intercostal space and the thoracic paravertebral space through the porous tissue surrounded by the costotransverse foramen and the costotransverse ligament [2]. Using fresh cadavers, they indicated that the likely site of action of this extensive delivery of injected local anesthetics is at the dorsal and ventral rami of the thoracic spinal nerves and, thus, it is expected to block the ventral ramus and the sympathetic fibers leading to effective management of somatic and visceral pains.

For this reason, shortly after its introduction, many researchers and clinicians have incorporated ESPB in their practices as part of multimodal analgesia after thoracic surgeries and even as a potential alternative to thoracic epidural block (TEB) or thoracic paravertebral block (TPVB). In fact, numerous studies on the use of ESPB (78 case reports, 5 cadaveric studies, and 2

Corresponding author: Seunguk Bang, M.D., Ph.D.

Department of Anesthesiology and Pain Medicine, Daejeon St. Mary's Hospital, College of Medicine, The Catholic University of Korea, 64 Daeheung-ro, Jung-gu, Daejeon 34943, Korea

Tel: 82-42-220-9046, Fax: 82-0504-272-6077

Email: seungukb@naver.com

ORCID: https://orcid.org/0000-0001-6609-7691

Received: December 18, 2018.

Accepted: December 18, 2018.

Korean J Anesthesiol 2019 February 72(1): 1-3

https://doi.org/10.4097/kja.d.18.00359 randomized controlled trials) have been reported in the last two years [3]. Most of these studies were on postoperative pain management after thoracic surgeries, including breast and lung surgeries, and abdominal surgeries, including intestine and kidney surgeries [3-5]. About $90 \%$ of the reported ESPB studies were performed at the thoracic level and about $80 \%$ of the reported cases could effectively control postoperative pain only with a single injection [3].

Currently, the application of the ESPB procedure has been extended to the lumbar and the cervical levels [1,6-8]. What could be the reasons for such interest in the ESPB procedure to warrant such massive attention from researchers and clinicians in a short period? First, with the ESPB, even a single injection can be dispersed in a cephalad and/or caudad manner to block multiple levels of nerves, unlike other conventional interfascial plane blocks [2]. Moreover, when compared with the other thoracic interfascial plane blocks which can only block the branches of the ventral ramus, ESPB can potentially block both the ventral ramus and the sympathetic fibers to control visceral pain [9]. Second, ESPB is relatively easier to perform when compared with other conventional blocks like the TEB or TPVB. Also, in ESPB, inserting and dwelling a catheter for continuous infusion can be done readily. Lastly, the ESPB procedure is expected to result in fewer complications, such as nerve palsy from a hematoma, or lung-related injuries, since the injection target of the block, the transverse process, is not in close proximity to vulnerable anatomical structures $[2,5]$.

Despite many advantages of the ESPB, however, caution is warranted with regards to its clinical use. First, the originality or the terminology of the ESPB is yet to be agreed and therefore the questions are asked of the advantage of the ESPB over the conventional blocks $[10,11]$. In fact, the ESPB shares some characteristics, such as the injection point and the spreading pattern, with the conventional interfascial plane blocks around the thoracolumbar fascia, such as the retrolaminar block and the quadratus lumborum block [12-15]. Second, the reproducibility of the anesthesia using the ESPB procedure has not been

(c) This is an open-access article distributed under the terms of the Creative Commons Attribution Non-Commercial License (http://creativecommons.org/ licenses/by-nc/4.0/), which permits unrestricted non-commercial use, distribution, and reproduction in any medium, provided the original work is properly cited. 
assessed due to the wide variation in analgesia effects reported when using this procedure. Also, even after the injection of an effective concentration of the local anesthetics using the ESPB technique, only vague methods like the conventional pinprick or cold ice test have been used to check for the range and effectiveness of blockage achieved. Despite this lack of comprehensive studies, however, the results in terms of pain alleviation reported with the use ESPB is profound. One hypothesis to explain this profound effect is that ESPB is a differential block mediated by the unmyelinated $\mathrm{C}$ fibers and not by the larger A-delta and A-gamma fibers [16-18]. Finally, although the ESPB procedure has been reported to relieve both visceral and somatic pains, there is still some variability in managing visceral pain. Some cadaveric studies have shown that the range of the ESPB spreads to the ventral rami at multiple levels, the neural foramina, and the epidural spaces [2,12]. However, according to Yang et al. [13], the spread was limited only to the ventral rami at multiple levels and not to the thoracic paravertebral space. Another study even reported that the range of the ESPB was mostly confined to the dorsal ramus and only about $10 \%$ involved the ventral ramus or the dorsal root ganglion [14].

As discussed, many researchers have endorsed the ESPB procedure solely based on empirical evidence of effective pain management. However, there are other researchers who do not acknowledge the value of the ESPB because its mechanism of pain relief is not fully understood [19]. The ESPB can be considered as a newly discovered alternative method for central neuraxial block with great potentials in the future. More studies to verify its utility and value is warranted as such studies would confirm or refute the empirical results obtained so far and, thus, guide clinical practice. If such studies confirm the benefits of ESPB, then it is very likely that ESPB will continue to be popular and eventually replace the conventional analgesic techniques such as the TEB and TPVB. As of now, without comprehensive studies evaluating its efficacy, it rests on the researchers and clinicians to decide whether to use ESPB or not. We should acknowledge that our insights on this new technique are limited; however, we should not deny the successes it has seen just because its entire mechanism underlying pain relieve has not been completely elucidated.

\section{References}

1. Elkoundi A, Bentalha A, El Kettani SE, Mosadik A, El Koraichi A. Erector spinae plane block for pediatric hip surgery. Korean J Anesthesiol 2019; 72: 68-71.

2. Forero M, Adhikary SD, Lopez H, Tsui C, Chin KJ. The erector spinae plane block: a novel analgesic technique in thoracic neuropathic pain. Reg Anesth Pain Med 2016; 41: 621-7.

3. Tsui BC, Fonseca A, Munshey F, McFadyen G, Caruso TJ. The erector spinae plane (ESP) block: A pooled review of 242 cases. J Clin Anesth 2018; 53: 29-34.

4. Kim E, Kwon W, Oh S, Bang S. The erector spinae plane block for postoperative analgesia afterpercutaneous nephrolithotomy. Chin Med J (Engl) 2018; 131: 1877-8.

5. Kwon WJ, Bang SU, Sun WY. Erector spinae plane block for effective analgesia after total mastectomy with sentinel or axillary lymph node dissection: a report of three cases. J Korean Med Sci 2018; 33: e291.

6. Kline J, Chin KJ. Modified dual-injection lumbar erector spine plane (ESP) block for opioid-free anesthesia in multi-level lumbar laminectomy. Korean J Anesthesiol 2018. Advance Access published on Nov 2, 2018. doi: 10.4097/kja.d.18.00289.

7. Tulgar S, Thomas DT, Suslu H. Ultrasound guided erector spinae plane block relieves lower cervical and interscapular myofascial pain, a new indication. J Clin Anesth 2018; 53: 74.

8. Evans HT, Leslie GJ, Rutka O, Keevil E, Burckett-St Laurent D. Bilateral erector spinae plane block for surgery on the posterior aspectof the neck: a case report. A A Pract 2018. Advance Access published on Nov 20, 2018. doi: 10.1213/XAA.0000000000000926.

9. Chin KJ, Malhas L, Perlas A. The erector spinae plane block provides visceral abdominal analgesia in bariatric surgery: a report of 3 cases. Reg Anesth Pain Med 2017; 42: 372-6.

10. Ueshima H, Otake H. Similarities between the retrolaminar and erector spinae plane blocks. Reg Anesth Pain Med 2017; 42: 123-4.

11. Murouchi T. Consideration of block nomenclature: erector spinae plane block or retrolaminar block? Reg Anesth Pain Med $2017 ; 42: 124$.

12. Adhikary SD, Bernard S, Lopez H, Chin KJ. Erector spinae plane block versus retrolaminar block: a magnetic resonance imaging and anatomical study. Reg Anesth Pain Med 2018; 43: 756-62.

13. Yang HM, Choi YJ, Kwon HJ, O J, Cho TH, Kim SH. Comparison of injectate spread and nerve involvement between retrolaminar and erector spinae plane blocks in the thoracic region: a cadaveric study. Anaesthesia 2018; 73: 1244-50.

14. Ivanusic J, Konishi Y, Barrington MJ. A cadaveric study investigating the mechanism of action of erectorspinae blockade. Reg Anesth Pain Med 2018; 43: 567-71.

15. Elsharkawy H, Pawa A, Mariano ER. Interfascial plane blocks: back to basics. Reg Anesth Pain Med 2018; 43: 341-6.

16. Ford DJ, Raj PP, Singh P, Regan KM, Ohlweiler D. Differential peripheral nerve block by local anesthetics in the cat. Anesthesiology 1984; 60: 28-33. 
17. Chin KJ, Adhikary SD, Forero M. Understanding ESP and fascial plane blocks: a challenge to omniscience. Reg Anesth Pain Med 2018; 43: 807-8.

18. Kunigo T, Murouchi T, Yamamoto S, Yamakage M. Injection volume and anesthetic effect in serratus plane block. Reg Anesth Pain Med 2017; 42: 737-40.

19. Cornish PB. Erector spinae plane block: the "happily accidental" paravertebral block. Reg Anesth Pain Med 2018; 43: 644-5. 